LS-109

E. A. Crosbie

March $1988 / 2$

\title{
A Positron Accumulator Ring for APS
}

\section{Introduction}

In the positron injection scheme described in the 1987 7-GeV Advanced Photon Source Conceptual Design Report, ${ }^{1}$ linac macropulses are injected once each second into RF buckets of the injector synchrotron at $450 \mathrm{MeV}$. After acceleration to $7 \mathrm{GeV}$, the eight bunches are transferred one at a time into designated RF buckets in the storage ring.

Two synchrotron RF systems are required for this injection procedure. A low frequency (39.22 MHz) system is used during injection to capture the $16.5 \mathrm{~ns}$ macropulses from the positron linac. After acceleration to $2.7 \mathrm{GeV}$, the length of each of the bunches is short enough so that a high frequency (352.96 MHz) RF system can be used for final acceleration to $7 \mathrm{GeV}$. With $1.55 \times 10^{9}$ positrons per bunch and $80 \%$ efficiency, the time required to fill the storage ring to $100 \mathrm{~mA}$ is $3.7 \mathrm{~min}$.

The addition of a small $450-\mathrm{MeV}$ positron accumulator ring (PAR) permits accumulation of the positrons from the linac during the acceleration cycle of the injector synchrotron. ${ }^{2}$ The pulse repetition rate of the postitron Iinac is $60 \mathrm{~Hz}$. The efght-pulse-per-second scheme described above has a linac duty factor of only $8 / 60=0.133$. By adding the accumulator ring to the system, the linac duty factor can be increased by a factor of 6 to 0.80 . With equal efficiency and charge per pulse, this results in a factor of 6 increase in the storage ring filling rate. 


\section{DISCLAIMER}

Portions of this document may be illegible in electronic image products. Images are produced from the best available original document. 
The new positron injection scheme is as follows. The cycle rate of the injector synchrotron is increased to $2 \mathrm{~Hz}$. During $0.4 \mathrm{sec}$ of each $0.5-\mathrm{sec}$ synchrotron cycle, 24 linac pulses are injected into the horizontal phase space of the PAR at a $60-\mathrm{Hz}$ rate. Each injected pulse occuples about $1 / 3$ of the circumference of the accumulator ring. After $0.1 \mathrm{sec}$ for longitudinal damping, the single accumulated bunch is transferred into one of the 352.96-MHz buckets of the injector synchrotron RF system. This single bunch is accelerated to $7 \mathrm{GeV}$ and transferred into the storage ring while the PAR accumulates the next bunch of positrons. Note that the injector synchrotron requires only the one high-frequency $\mathrm{RF}$ system.

\section{Positron Accumulator Ring Description}

\section{A. Introduction}

The rate at which positrons can be injected into the horizontal phase space of the accumulator ring depends on the damping rate of the horizontal betatron oscillations. The amount by which these oscillations are damped between successive Injections limits the separation of the bumped orbit from the septum of the injection magnet. This separation in turn determines the horizontal aperture of the ring. Therefore, the damping rate must be as large as possible.

The horizontal damping time constant $\tau_{x}$ is given by

$$
\tau_{x}=\frac{4 \pi R \rho}{26.55 J_{x} E^{3}} \frac{\mathrm{GeV}^{3} \mathrm{~ms}}{\mathrm{M}^{2}}, 3
$$

where $2 \pi R$ is the circumference of the ring,

$\rho$ is the bending radius in each dipole, 
$E$ is the positron energy,

and

$$
\begin{aligned}
& J_{x}==1-\frac{1}{2 \pi} \int_{m a g} \frac{D(s)}{\rho}(1-2 n) d s, \\
& D(s) \text { is the dispersion function, } \\
& n=\frac{-\rho B^{\prime}(x)}{B_{0}} \text { (field index), }
\end{aligned}
$$

and $B^{\prime}(x)$ is the radial gradient in the bending magnets.

In addition to the horizontal oscillation damping required for injection, the length of the single bunch in the ring must be compressed from about $1 / 3$ of the revolution time of the PAR to a length that can be injected without loss into the 353-MHz RF buckets of the injector synchrotron. This compression of the bunch length is accomplished by damping of the energy spread. The time allowed for the damping for 24 pulses injected at $60-\mathrm{Hz}$ and 2-Hz cycle rate for the injector synchrotron is 0.1 sec. The energy damping time constant is given by

$$
\tau_{\mathrm{E}}=\tau_{\mathrm{x}} \mathrm{J}_{\mathrm{x}} / \mathrm{J}_{\mathrm{E}}
$$

where $J E=3-J_{x}$.

At $450 \mathrm{MeV}(B p=1.501 \mathrm{Tm})$, a small damping time constant requires high magnetic fields in the bending magnets. We have chosen $B=1.476 \mathrm{~T}(\rho)$ $1.0186 \mathrm{~m})$. The circumference of the ring must also be as small as possible and still leave room for quadrupoles, sextupoles, injection and extraction magnets, orbit correctors and RF cavities. We have chosen $2 \pi R=30.5768 \mathrm{~m}$, which is $1 / 12$ the circumference of the injector synchrotron. 
To further decrease the horizontal damping time constant, the field Index in the bending magnets is 0.6 . For the lattice described in the next section, $J_{S}=1.257, J_{E}=1.743$, and $\tau_{x}=20.49 \mathrm{~ms}, \tau_{E}=14.77 \mathrm{~ms}$.

\section{B. Lattice}

A plan view of the PAR is shown in Fig. 1. The eight bending magnets are arranged in a two-period configuration with two long straight sections. One of the long straight sections is used for injection and extraction. The other long straight section contains the RF system. The component parameter 1 ist for $1 / 2$ period is shown in Table $I$. The lattice functions $\beta_{x}, \beta_{y}$ and dispersion function $D$ are shown in Fig. 2 . The dispersion function is zero in the two long straight sections.

The horizontal and vertical tunes for the parameters of Table I are $v_{x}=2.19, v_{y}=1.27$. A list of the performance characteristics for the ring is shown in Table II. One notes that the vertical chromaticity is positive. To correct both chromaticities to zero requires two families of sextupoles, $\mathrm{s}_{1}=0.225 / \mathrm{m}^{2}$ and $\mathrm{s}_{2} / 2=0.435 / \mathrm{m}^{2}$.

A list of all the PAR magnets is given in Table III.

\section{RF Capture and Bunch Length Danping}

Each macropulse from the $450-\mathrm{MeV}$ positron Iinac is $30-\mathrm{ns}$ long. The Injected pulses are captured by a first harmonic $9.8045 \mathrm{MHz}$ RF system. Ninety-five percent of the injected beam is contained within an energy spread of $\pm 1 \%$. (An energy damping system is included in the injection Iine design, which may reduce this to $\pm 0.5 \%$.)

Once each cycle of the 2-Hz Injector synchrotron, 24 macropulses are Injected Into the horizontal phase space of the PAR at a $60-\mathrm{Hz}$ rate. This 
leaves $100 \mathrm{~ms}$ for the final damping of the single bunch to a length short enough to be transferred to the 2.83-ns (353-MHz) injector synchrotron RF buckets.

The RF voltage applied during the injection into the PAR must be just large enough for efficient capture without producing too much increase in the energy spread. The latter condition is important because of the aperture requirements for injection into the horizontal phase space. The dispersion function has a maximum value of $3.35 \mathrm{~m}$.

Figure 3 shows a $\pm 1 \%, 30-n s$ injected pulse in a $40-k V$, firstharmonic PAR bucket. The bucket contour that just encloses the pulse has $\Delta \tau=60$ ns and $\Delta E / E= \pm 1.2 \%$. At least $95 \%$ of the injected beam should be contained within this contour.

The longitudinal phase space damping can be determined by

$$
\begin{aligned}
& \sigma_{E} / E(t)=\sqrt{\left(\sigma_{E} / E(\infty)\right)^{2}+\left(\left(\sigma_{E} / E(0)\right)^{2}-\left(\sigma_{E} / E(\infty)\right)^{2}\right) \exp \left(-2 t / \tau_{E}\right)} \\
& \sigma_{\tau}(t)=\frac{1}{2 \pi f_{S} \gamma_{T}^{2}} \sigma_{E} / E(t)
\end{aligned}
$$

where

$$
\sigma_{E} / E(\infty)=\sqrt{\frac{0.384}{\rho J_{E}}} \frac{E}{0.511} \times 10^{-3}=0.41 \times 10^{-3}(\rho(m), E(G e V))
$$

is the natural (completely damped) energy spread in the ring, $\gamma_{\mathrm{T}}$ is the transition $r$, and $f_{S}$ is the synchrotron frequency.

For example, with $40 \mathrm{kV}$, the synchrotron frequency is $19.1 \mathrm{kHz}$. Starting with $\sigma_{E} / E(0)=12 / \sqrt{6} \times 10^{-3}$, each of the injected pulses will damp to $\sqrt{6} \sigma_{E} / E=4.0 \times 10^{-3}, \sqrt{6} \sigma_{\tau}=8.96 \mathrm{~ns}$ during the $16.7 \mathrm{~ms}$ between injections. 
During the $100 \mathrm{~ms}$ allowed for final damping, $\sigma_{E} / E$ is reduced to the natural value of $0.41 \times 10^{-3}$. If the $R F$ voltage remains at $40 \mathrm{kV}$, the final bunch length is $\sigma_{\tau}=0.92 \mathrm{~ns}$, which is $1 / 3.1$ of the $353-\mathrm{MHz}$ injector synchrotron bucket (i.e., I.S. bucket $= \pm 1.55 \sigma_{\tau}$ ). If the PAR first harmonic voltage is raised to $100 \mathrm{kV}$ during the final damping, the synchrotron frequency is $30.2 \mathrm{kHz}$ and the final bunch length $\sigma_{\tau}$ becomes $0.58 \mathrm{~ns}$ or $1 / 4.88$ of the injector synchrotron bucket.

The bunch length damping provided by the first harmonic system is not adequate for efficient capture in the injector synchrotron. Therefore, a twelfth harmonic (117.654 MHz) $30-\mathrm{kV} \mathrm{RF}$ system has been added to PAR for the final damping. This system is turned on $50 \mathrm{~ms}$ after the injection of the last pulse. The first harmonic system damps the beam to $\sigma_{E} / E=0.44 \times 10^{-3}$ and $\sigma_{\tau}=0.99 \mathrm{~ns}$. With the first harmonic system still on, the twelfth harmonic system is turned on with phase equals $\pi$ at the bunch center. Figure 4 shows the $\sqrt{6} \sigma$ contour of damped beam in the combined $40-\mathrm{kV}$ first harmonic and $30-\mathrm{kV}$ twelfth harmonic bucket.

The capture of the bunch in this combined bucket should be adiabatic. Even if the capture is completely non-adiabatic, the remaining $50 \mathrm{~ms}$ is long enough to damp the energy spread to the natural value of $\sigma_{E} / E$ $=0.41 \times 10^{-3}$. Since the combined system has a synchrotron frequency of $60.6 \mathrm{kHz}$, the final bunch length is $\sigma_{\mathrm{T}}=0.29 \mathrm{~ns}$ or $1 / 9.77$ of the injector synchrotron bucket. Figure 5 shows the phase space contours for the $\pm \sigma$, and $\pm \sqrt{6} \sigma$ of the PAR bunch in the injector synchrotron 100-kV RF bucket.

\section{Injection}

The maximum amplitude of the horizontal oscillations in the PAR is determined by the separation of the injection and bumped orbit positions at 
the injection septum magnet. This separation is limited by the damping of the horizontal oscillations in the $16.7 \mathrm{~ms}$ between each injection. The conditions can be quantified as follows. Let $x_{0}, x_{S}$, and $x_{B}$ be the distances from the central orbit to the injected beam center, the inner edge of the septum magnet, and the bumped orbit, respectively. The relations between these quantities may be written as follows:

$$
x_{0}-A-s \geqslant x_{S} \geqslant x_{B}+D\left(x_{0}+A-x_{B}\right)
$$

where

$$
A=\sqrt{\beta_{\text {ox }} \varepsilon}=3.70 \mathrm{~mm}
$$

$\beta_{\text {ox }}$ is the horizontal lattice function parameter at the septum location

$$
(2.074 \mathrm{~m}) \text {, }
$$

$E$ is the $95 \%$ emittance of the injected beam $(6.6 \mathrm{mrad} \mathrm{mm})$,

$s$ is the septum thickness ( $2 \mathrm{~mm})$, and

$D=\exp \left(-16.7 \mathrm{~ms} / \tau_{\mathrm{x}}\right)=0.443$

$\tau_{\mathrm{x}}=20.49 \mathrm{~ms}$.

Choosing $x_{S}=30 \mathrm{~mm}$, both conditions are satisfied with $x_{0}=2 x_{B}$ $=36.7 \mathrm{~mm}$. Figure 6 shows the horizontal phase space that can be occupied by the beam at the septum magnet. The beam is first injected at the outside of the septum magnet with the local orbit displaced so that coherent oscillations occur about the bumped orbit location $x_{b}$. During subsequent turns with the orbit bump magnets turned off, the $95 \%$ profile of the injected beam will, before damping, be located anywhere in a phase space ring having radii of 
$x_{0}-x_{B} \pm A$. After $1 / 60 \mathrm{sec}$ of damping, the ring size is reduced enough so that the maximum extent of the beam misses the septum magnet when the orbit warp is restored for injection of the next pulse. Pulses that have been injected previous to the pulse under consideration will have been damped for a longer time and will occupy the space inside the rings shown in the figure. (Based on the calculated natural emittance of the lattice, the horizontal oscillations showed damp to a final value of $\sigma_{x}=0.88 \mathrm{~mm}$. )

The maximum extent of the horizontal oscillations of each injected pulse is $\pm 21 \mathrm{~mm}$ at the septum magnet. Because of a larger $\beta_{X}$, this width increases to $\pm 35 \mathrm{~mm}$ at one-fourth of the circumference upstream and downstream of the septum. At this location, the dispersion function has its largest value of $3.35 \mathrm{~m}$. If the energy spread of the injected beam is $\pm 1 \%$, the maximum total aperture required for injection is $\pm 50 \mathrm{~mm}$. For this reason, the horlzontal aperture of the vacuum chamber is $12 \mathrm{~cm}$. The vertical gap is $3.6 \mathrm{~cm}$. Two kicker magnets are used to produce the bumped orbit at the Injection magnet. One each of these is located $90^{\circ}$ in horizontal betatron phase upstream and downstream of the injection septum magnet. The positions and the bumped orbit are shown in Fig. 7. They are separated by $9.12 \mathrm{~m}$. Therefore, a $30.4-\mathrm{ns}$ time difference is required between the power pulses to the two kickers.

The rise time of the injection kicker magnetic fields is not important for the injection process. They should be on for about 80 ns to allow for up to a 50-ns injection pulse length. If the fall-off time of the Injection kicker fields is $90 \mathrm{~ns}$, the head of a 50-ns positron pulse will return to each kicker when its magnetic field has been reduced by about a factor of 2. With the bumped orbit displacement reduced by a factor of 2 and taking into account a $68^{\circ}$ phase rotation of the coherent betatron oscillation, 
the head of the injected phase clears the septum by 10 mm on the first turn after Injection.

Figure 8 shows a typical injection kicker pulse used to produce the bumped orbit. Because one of the injection kickers is also used to help extract the beam, the rise time of the kicker fields is shown as 90 ns.

During each $0.5-\mathrm{sec}$ cycle of the injection synchrotron, the PAR injection kickers are pulsed at about $60 \mathrm{~Hz}$ for the $0.4 \mathrm{sec}$ required to accumulate 24 Iinac pulses. They can then be turned off for the 0.1 sec of final bunch length damping. However, with the Injection kickers on, the revolution time is increased by only $0.085 \mathrm{~ns}$. Since this increase occurs for only two to three turns at a 60-Hz rate, it has practically no effect on the synchrotron oscillations. Therefore, it may be more convenient to operate the injection kickers continuously.

The kicker strength required to produce a bumped orbit of $18.4 \mathrm{~mm}$ at the septum magnet is $171 \mathrm{Gm}$. The designed kickers are 35-cm long and are capable of producing fields of $600 \mathrm{G}$.

\section{Extraction}

The positron bunch is extracted by using the upstream injection kicker and a third identical kicker located just downstream of the injection kicker (F1gs. 7 and 8 ).

If the injection kickers are already on (as they would be with continuous $60-\mathrm{Hz}$ operation), extraction is accomplished by pulsing the third magnet with a 90 -ns rise time. If the injection kickers are off during the final bunch length damping time, the two upstream kickers are pulsed together to extract the beam. The combination of the two kickers causes the positron 
bunch to enter the aperture of the injection septum magnet, which then becomes the final extraction magnet.

In section IV, the horizontal position of the injected beam was chosen to be two times that of the bumped orbit at the septum magnet. This was done so that the double kick produced by one of the injection kickers and an identical extraction kicker would cause the extraction point to be the same source at the injection point. Because of differences of lattice phase and $\beta_{x}$ at the two kickers, the extraction point lies about $5 \mathrm{~mm}$ outside the injection point if both kickers have the same fields used by the injection kickers for Injection. To make the extraction point the same as the injection point, the extraction kicker should be pulsed to about $78 \%$ of the field in the injection kicker. The extracted beam enters the septum magnet with a small 2.3 mrad positive angle.

\section{Injection Extraction Septum Magnet}

The same septum magnet is used for both injection into and extraction from the PAR. Both beams must clear the yokes of either the downstream or upstream bending magnet. These magnets are at a distance of $2.26 \mathrm{~m}$ from the center of the injection straight section and have yokes that extend to $40 \mathrm{~cm}$.

The injection/extraction angle for the PAR is $0.2 \mathrm{rad}\left(11.5^{\circ}\right)$. The magnet is $0.4 \mathrm{~m}$ long, has a field value of $0.75 \mathrm{~T}$, and a septum thickness of $2 \mathrm{~mm}$. The horizontal and vertical apertures are $7 \mathrm{~cm}$ and $2 \mathrm{~cm}$, respectively. The magnet operates continuously at $60 \mathrm{~Hz}$. 


\section{Orbit Corrections}

The amplification factors for focusing element displacements for the PAR are 4.0 and 6.5 for the' horizontal and vertical plane, respectively. Horizontal and vertical orbit corrections are provided by five dipoles and six beam position monitors for each plane in each of the two periods (see Fig. 1). The correction dipoles are located in the multipole correction magnets.

\section{Computer simulations of ten sample machines with 1-mm rms magnet}

displacement errors and $10^{-3}$ rms $\frac{\Delta B}{B}$ and dipole roll errors produced rms distortions of about $7 \mathrm{~mm}$ in both planes. The largest single orbit distortions in the ten samples was about $18 \mathrm{~mm}$. The dipole strengths required to correct the orbits to better than $0.1 \mathrm{~mm}$ had rms averages of about $1 \mathrm{kG} \mathrm{cm}$. The largest single corrector strength in the ten samples was $2.9 \mathrm{kG} \mathrm{cm}$. The dipole correctors in the multipole magnets are designed to produce $4 \mathrm{kG} \mathrm{cm}$.

\section{Stored Beam Current}

The total number of positrons injected into the PAR can be as large as $3.6 \times 10^{10}$ (24 pulses at $\left.1.5 \times 10^{9} / \mathrm{pulse}\right)$. The average beam current $\overline{\mathrm{I}}$ is $56.5 \mathrm{~mA}$. As the pulse is damped in the ring, the peak current increases. For a gaussian distribution, the peak current is given by

$$
I_{p}=\frac{\bar{I} T}{\sqrt{2 \pi} \sigma_{\tau}}
$$

where $T$ is the revolution time (102 ns). 
At the time of switch-on of the twelfth harmonic cavity, almost all of the injected pulses will have damped to the limit of $\sigma_{\tau}=0.92 \mathrm{~ns}$, producing a peak current $I_{p}=2.45 \mathrm{~A}$. After further damping in the two-cavity system, $\sigma_{\tau}$ becomes $0.29 \mathrm{~ns}$ and the peak current is increased to $7.8 \mathrm{~A}$. The energy spread at this time is $\sigma_{E} / E=0.41 \times 10^{-3}$.

The impedance limit for longitudinal stability is customarily

written as

$$
\left|\frac{Z_{n}}{\mathrm{n}}\right|<\frac{\mathrm{E}}{\gamma_{\mathrm{T}}^{2} \text { Ip }}\left(\frac{\Delta \mathrm{p}}{\mathrm{p}}\right)^{2}
$$

where $\frac{\Delta p}{p}$ is the full width at half maximum $\left(2.355 \sigma_{E} / E\right)$.

On substitution, the calculated stability limit impedance is

$$
\left|\frac{Z_{\|}}{n}\right|<14.5 \Omega
$$


Table I

Positron Accumulator Ring Lattice Components

1/4 Machine

$\mathrm{B} \rho=1.5010 \operatorname{Tm}(0.45 \mathrm{GeV})$

\begin{tabular}{|c|c|c|c|}
\hline Element & & $\begin{array}{l}\text { Length } \\
\text { (m) }\end{array}$ & \\
\hline Drift & Ll & 1.7092 & \\
\hline Multipole & & 0.20 & \\
\hline Drift & & 0.10 & \\
\hline Quadrupole & Q1 & 0.25 & $\mathrm{~B}^{\prime} / \mathrm{B} \rho=0.543 \mathrm{~m}^{-2}$ \\
\hline Drift & & 0.20 & \\
\hline Magnet & & 0.80 & $\rho=1.01859 \mathrm{~m} \quad \frac{\rho B^{2}}{B}=-0.6$ \\
\hline Drift & & 0.20 & \\
\hline Quadrupole & Q2 & 0.25 & $\mathrm{~B}^{\mathrm{T}} / \mathrm{B} \rho=1.470601 \mathrm{~m}^{-2}$ \\
\hline Drift & & 1.39 & \\
\hline Multipole & $\mathrm{SI}$ & 0.20 & \\
\hline Drift & & 0.20 & \\
\hline Quadrupole & Q3 & 0.25 & $\mathrm{~B}^{\prime} / \mathrm{B} \rho=-1.360689 \mathrm{~m}^{-2}$ \\
\hline Drift & & 0.20 & \\
\hline Magnet & & 0.80 & $\rho=1.01859 \mathrm{~m} \quad \frac{\rho B^{\prime}}{B^{\prime}}=-0.6$ \\
\hline Drift & & 0.20 & \\
\hline Quadrupole & Q4 & 0.25 & $\mathrm{~B}^{\prime} / \mathrm{B} \rho=1.384567 \mathrm{~m}^{-2}$ \\
\hline Drift & & 0.345 & \\
\hline \multirow[t]{2}{*}{ 1/2 Multipole } & $\mathrm{S} 2$ & 0.10 & \\
\hline & Reflect & & \\
\hline TOTAL & & 7.6442 & \\
\hline
\end{tabular}


Table II

Parameters for the Positron Accumulator Ring

\begin{tabular}{|c|c|c|}
\hline \multicolumn{2}{|l|}{ Circumference (m) } & 30.5768 \\
\hline \multicolumn{2}{|l|}{ Revolution Time (ns) } & 101.994 \\
\hline \multicolumn{2}{|l|}{ Energy (MeV) } & 450 \\
\hline \multicolumn{2}{|l|}{ No. of Cells } & 2 \\
\hline \multicolumn{2}{|l|}{ No. of Dipoles } & 8 \\
\hline \multicolumn{2}{|l|}{ Dipole Field B (T) } & 1.476 \\
\hline \multicolumn{2}{|l|}{ Bend Radius $\rho$ (m) } & 1.0186 \\
\hline \multicolumn{2}{|l|}{ Field Index $\left(-\rho B^{\prime} / B\right)$} & 0.6 \\
\hline \multicolumn{2}{|l|}{ No. of Quadrupoles } & 16 \\
\hline \multicolumn{2}{|l|}{ Tunes $\nu_{\mathrm{x}} / \nu_{\mathrm{y}}$} & $2.19 / 1.27$ \\
\hline \multicolumn{2}{|l|}{ Transition Gamma $\left(\gamma_{\mathrm{T}}\right)$} & 1.93 \\
\hline \multicolumn{2}{|l|}{ Chromaticities $\left(\xi_{x} / \xi_{y}\right)$} & $-2.70 / 1.05$ \\
\hline \multicolumn{2}{|c|}{ Partition Numbers $\mathrm{Jx} / \mathrm{Jy} / \mathrm{J}_{\mathrm{E}}$} & $1.257 / 1.000 / 1.743$ \\
\hline \multicolumn{2}{|c|}{ Damping Time Constants $\tau_{x} / \tau_{y} / \tau_{E}$ (ms) } & $20.49 / 25.75 / 14.77$ \\
\hline \multicolumn{2}{|c|}{ Energy Loss per Turn (keV) } & 3.56 \\
\hline \multirow{2}{*}{\multicolumn{2}{|c|}{$\begin{array}{l}\text { Natural Emittance } \varepsilon \text { (mm mrad) } \\
\sigma E / E \text { (damped) }\end{array}$}} & 0.37 \\
\hline & & $0.41 \times 10^{-3}$ \\
\hline \multicolumn{3}{|l|}{ RF Systems } \\
\hline \multicolumn{3}{|l|}{ System I } \\
\hline $\mathrm{f}$ & $(\mathrm{MHz})$ & 9.8045 \\
\hline $\mathrm{h}$ & & 1 \\
\hline $\mathbf{v}$ & $(\mathrm{kV})$ & 40 \\
\hline $\mathrm{f}_{\mathrm{s}}$ & $(\mathrm{kHz})$ & 19.1 \\
\hline$\sigma_{\tau}$ (damped) & (ns) & 0.92 \\
\hline \multicolumn{3}{|l|}{ System II } \\
\hline $\mathbf{f}$ & $(\mathrm{MHz})$ & 117.654 \\
\hline $\mathrm{h}$ & & 12 \\
\hline$v$ & $(\mathrm{kV})$ & 30 \\
\hline$f_{s}$ & $(\mathrm{kHz})$ & $60.5 *$ \\
\hline$\sigma_{\tau}$ (damped) & (ns) & $0.29 *$ \\
\hline
\end{tabular}

*System I and II both on. 


\section{Table III}

\section{Magnet Summary}

Main Dipoles (DC)

$$
\text { \#8 } \quad \begin{aligned}
& \ell=0.8 \mathrm{~m} \\
& \rho=1.0186 \mathrm{~m} \\
& B=1.4736 \mathrm{~T} \\
& \mathrm{~B}^{\prime}=-0.8680 \mathrm{~T} / \mathrm{m},\left(\frac{\rho B^{\prime}}{\mathrm{B}}=-0.6\right) \\
& \text { Aperture Vacuum chamber, } 12 \mathrm{~cm} \times 3.6 \mathrm{~cm}
\end{aligned}
$$

Quadrupoles (DC)

$$
\text { \#16 } \begin{aligned}
& \ell=0.25 \mathrm{~m} \\
& B^{*}=4 \mathrm{~T} / \mathrm{m}
\end{aligned}
$$

Multipoles (DC)

$$
\begin{aligned}
& \text { \#12 } \quad l=0.2 \mathrm{~m} \\
& \text { Dipole, } 0.02 \mathrm{~T} \\
& \text { Sextupole, } 10 \mathrm{~T} / \mathrm{m}^{2}\left(=10 \mathrm{G} / \mathrm{cm}^{2}\right)
\end{aligned}
$$

Kickers

$$
\text { \#3 } \quad \begin{aligned}
& \ell=0.35 \mathrm{~m} \\
& \text { B }=\frac{600 \mathrm{G}}{} \\
& \text { Rise, Fall times, } 90 \mathrm{~ns} \\
& \text { Rep. Rate, } 60 \mathrm{~Hz} \\
& \text { Aperture, } 8 \mathrm{~cm} \times 3.6 \mathrm{~cm}
\end{aligned}
$$

Pulsed Septum

$$
\text { \#1 } \quad \begin{aligned}
& \ell=0.4 \\
& B=0.75 \mathrm{~T} \\
& \text { Septum, } 2 \mathrm{~mm} \\
& \text { Aperture, } 7 \mathrm{~cm} \times 3.6 \mathrm{~cm}
\end{aligned}
$$


References

1. $7 \mathrm{GeV}$ Advanced Photon Source Conceptual Design Report, Argonne National Laboratory Report ANL-87-15 (April 1987).

2. A. Frebel and G. Hemmie, "PIA, The Positron Intensity Accumulator for the PETRA Injection," IEEE Transactions on Nuclear Science, Vol. NS-26, No. 3 (June 1979).

3. M. Sands, "The Physics of Electron Storage Rings," SLAC Report 121 (1970). 


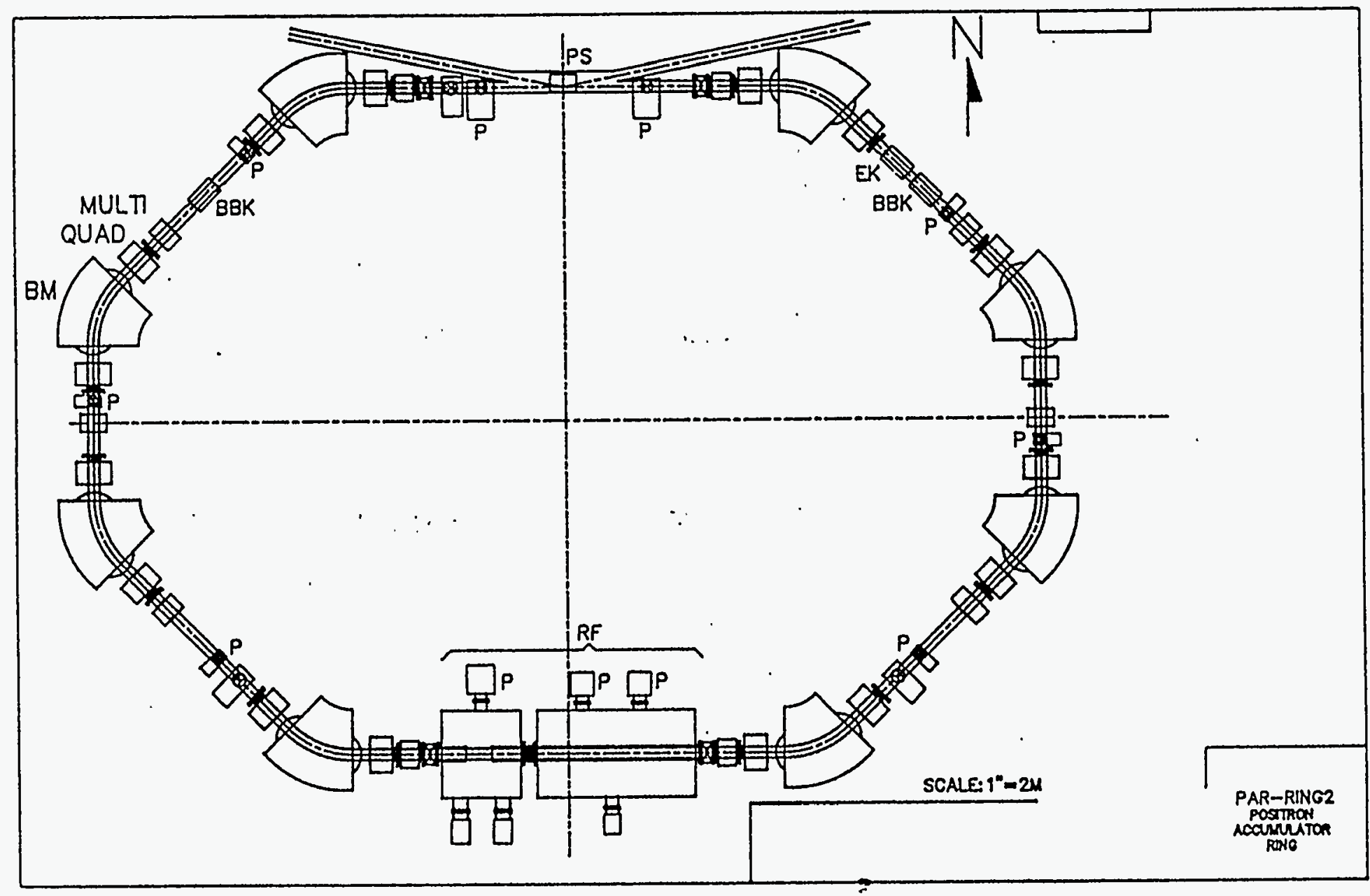

Fig. 1. Positron accumulator ring components. 


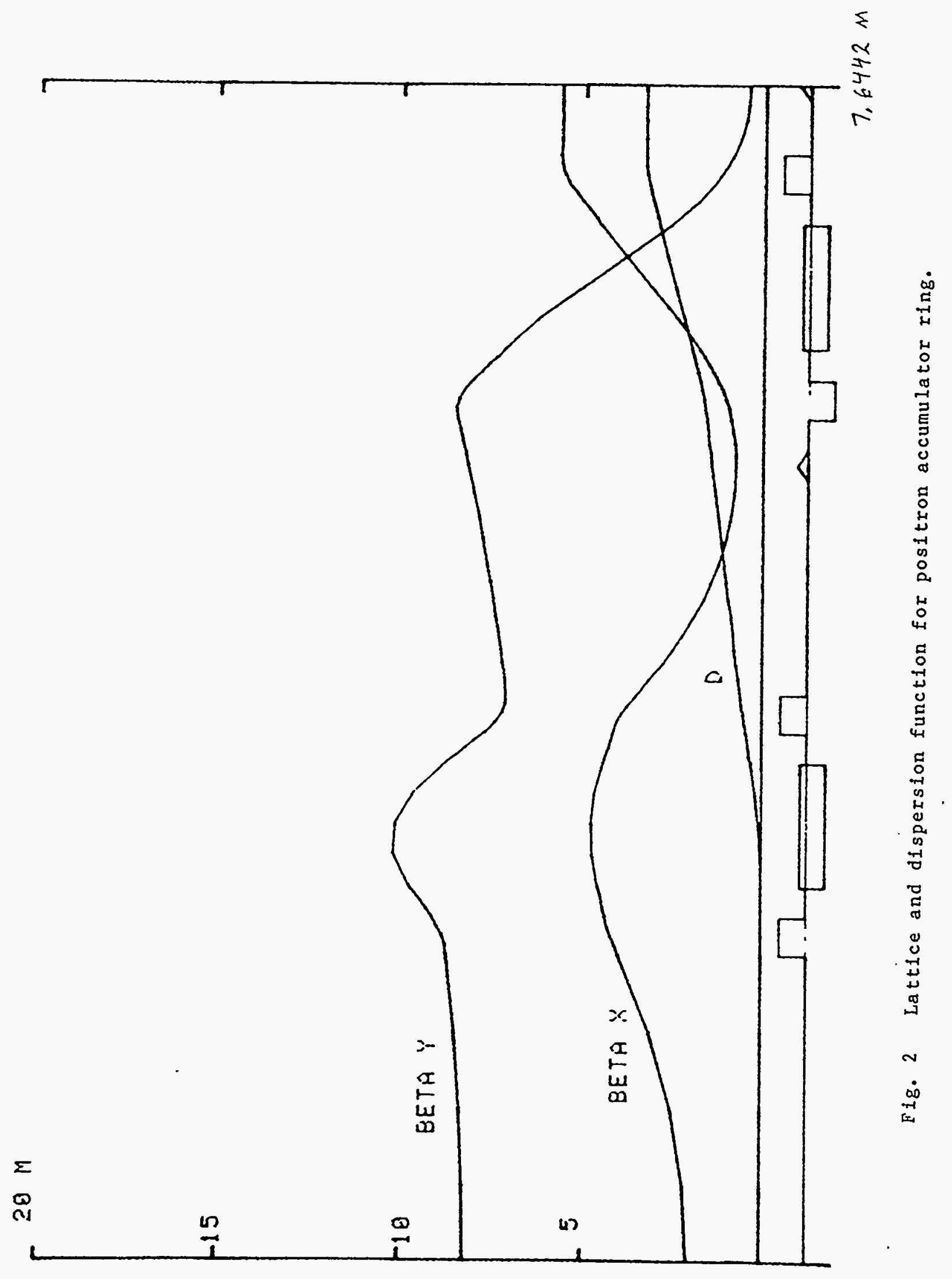




$$
\theta
$$




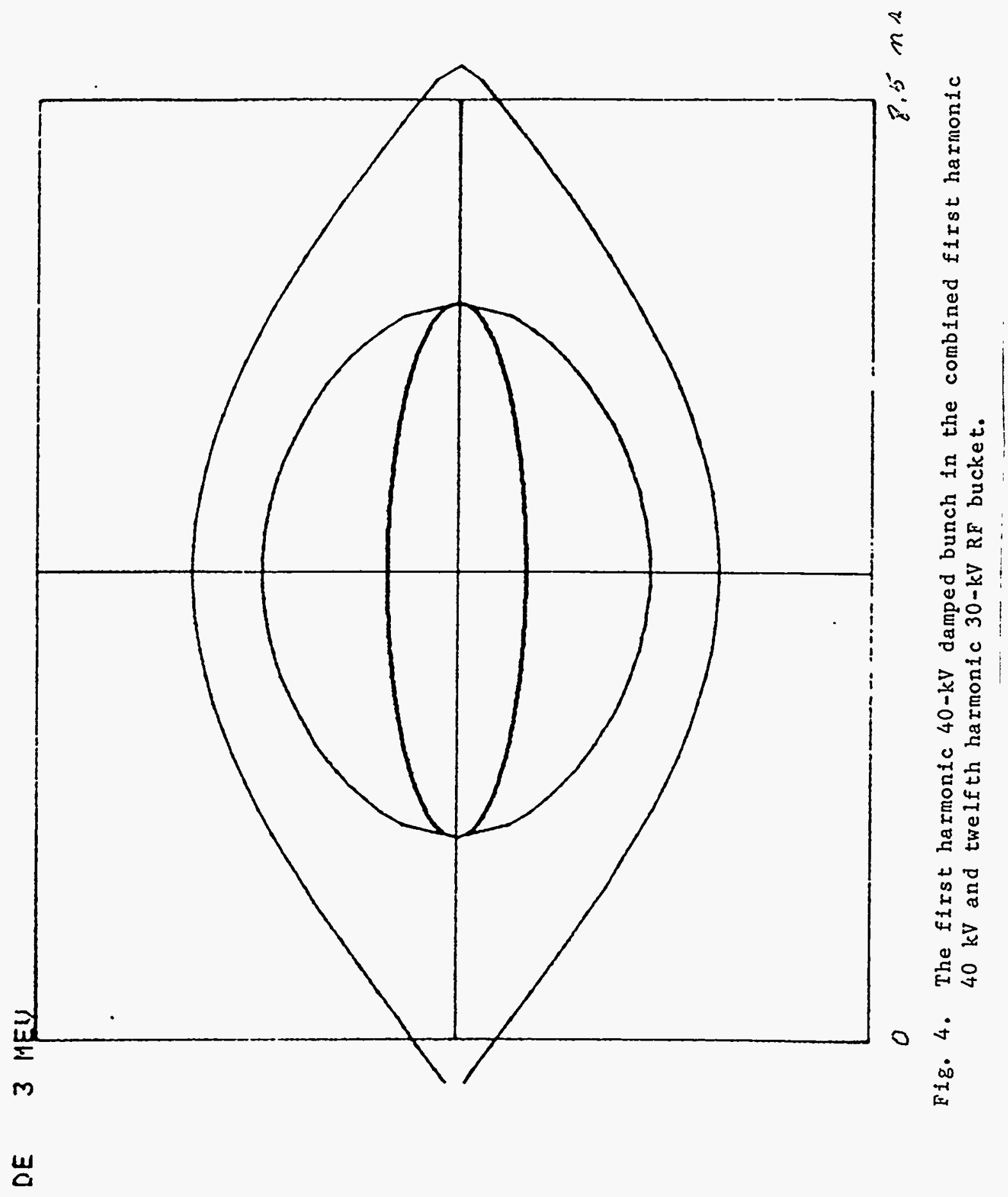




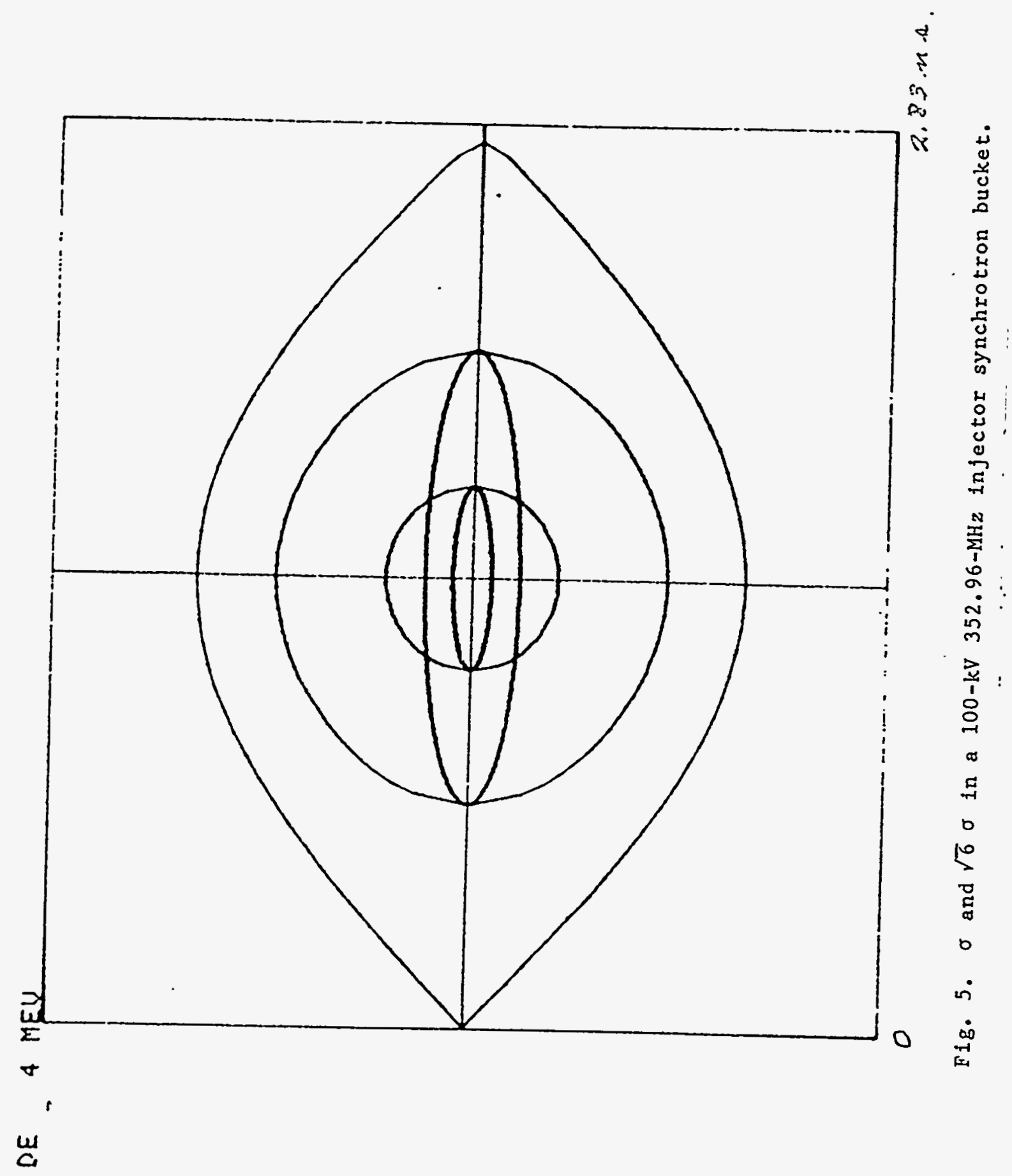




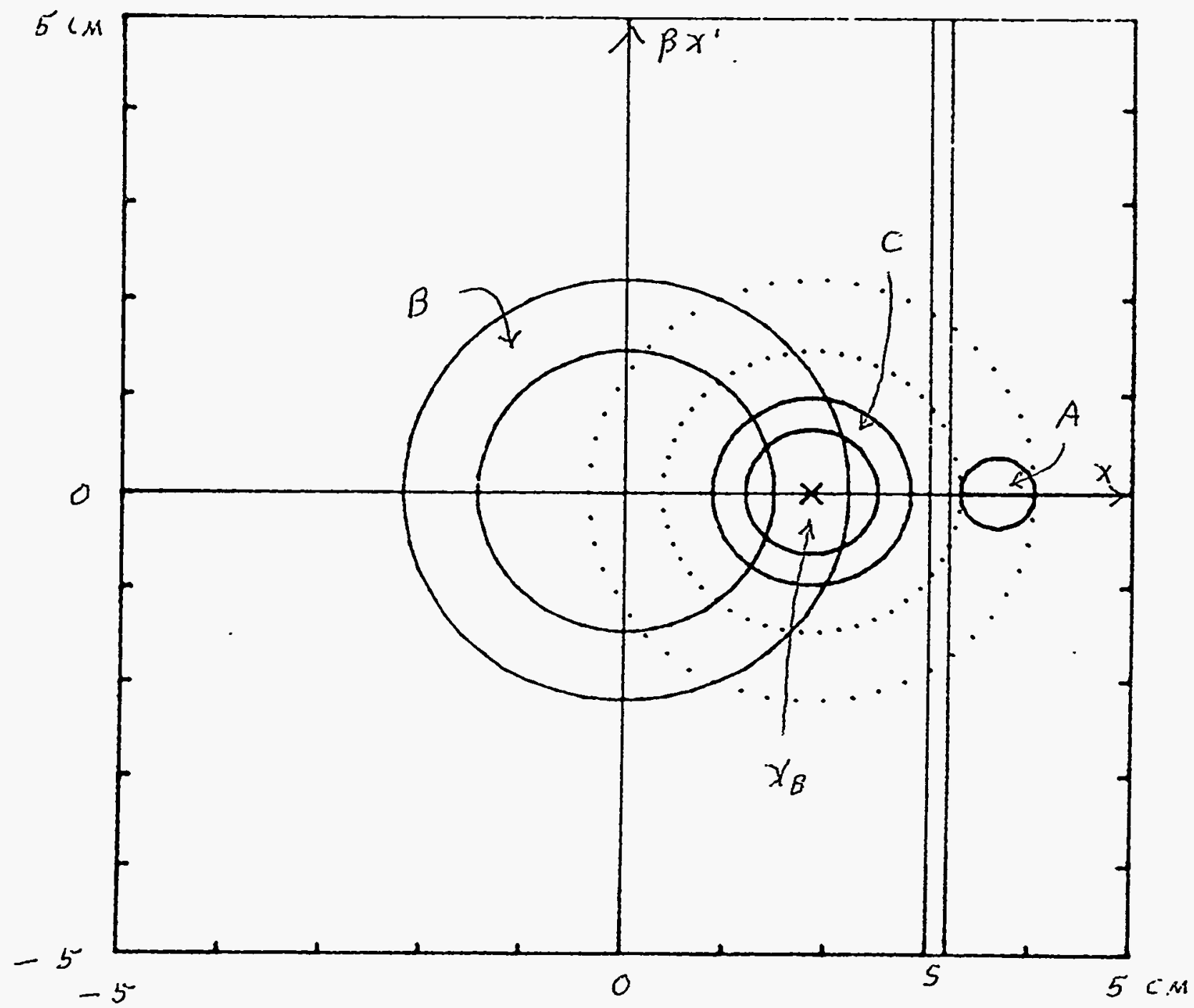

Fig. 6. Horizontal phase space at the injection septum magnet.

A: Injected beam

$S:$ Septum

$x_{B}$ : Bumped orbit position

$B$ : Posible phase space occupied by the injected beam before damping with the beam bumper magnets turned off.

C: Possible phase space occupied by injected beam after $16.7 \mathrm{~ms}$ of damping with the beam bumper magnets turned on. 


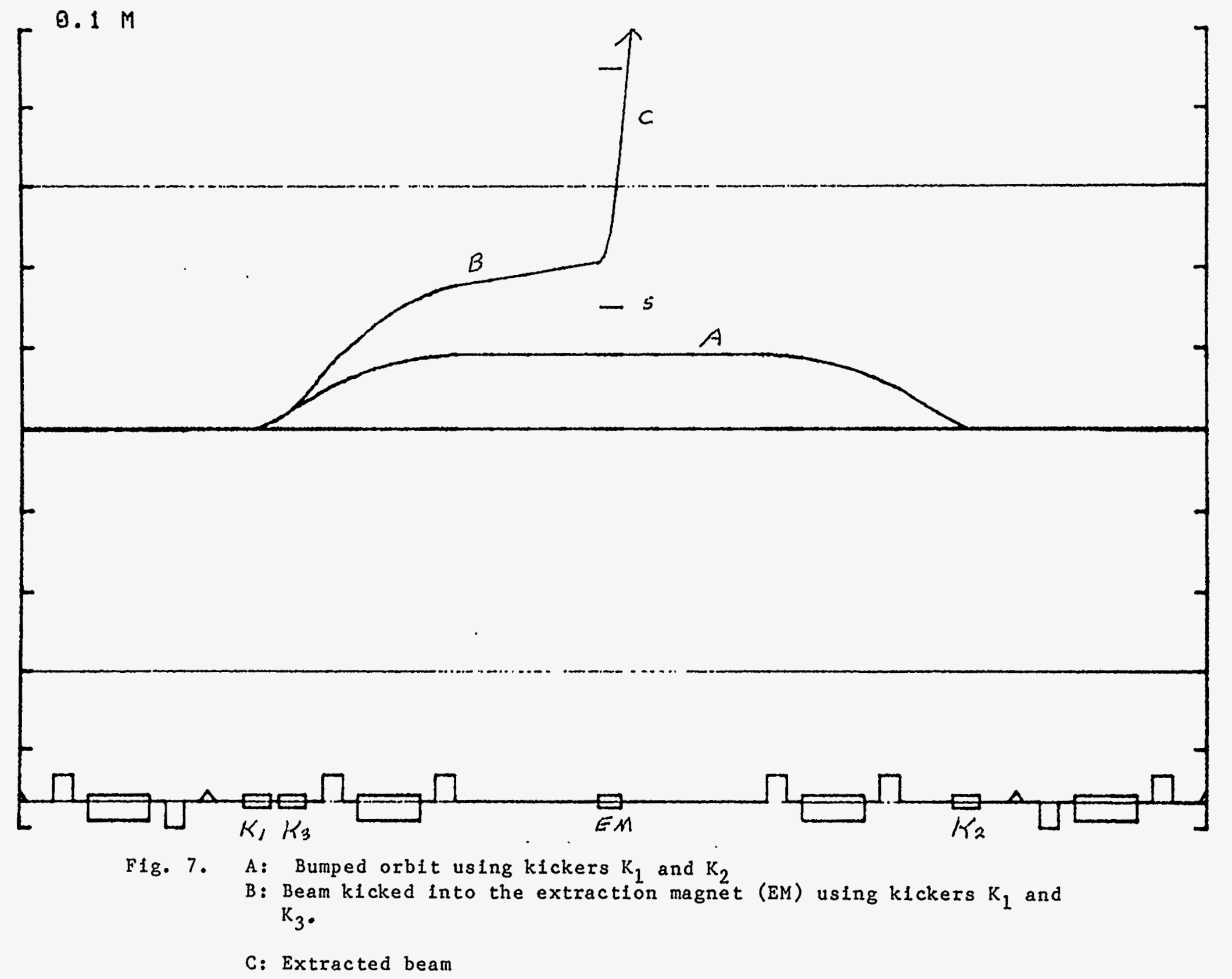



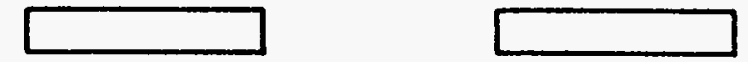

INJECTED BEAM

PULSE
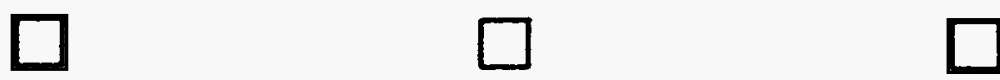

COASTING BEAM

PULSE
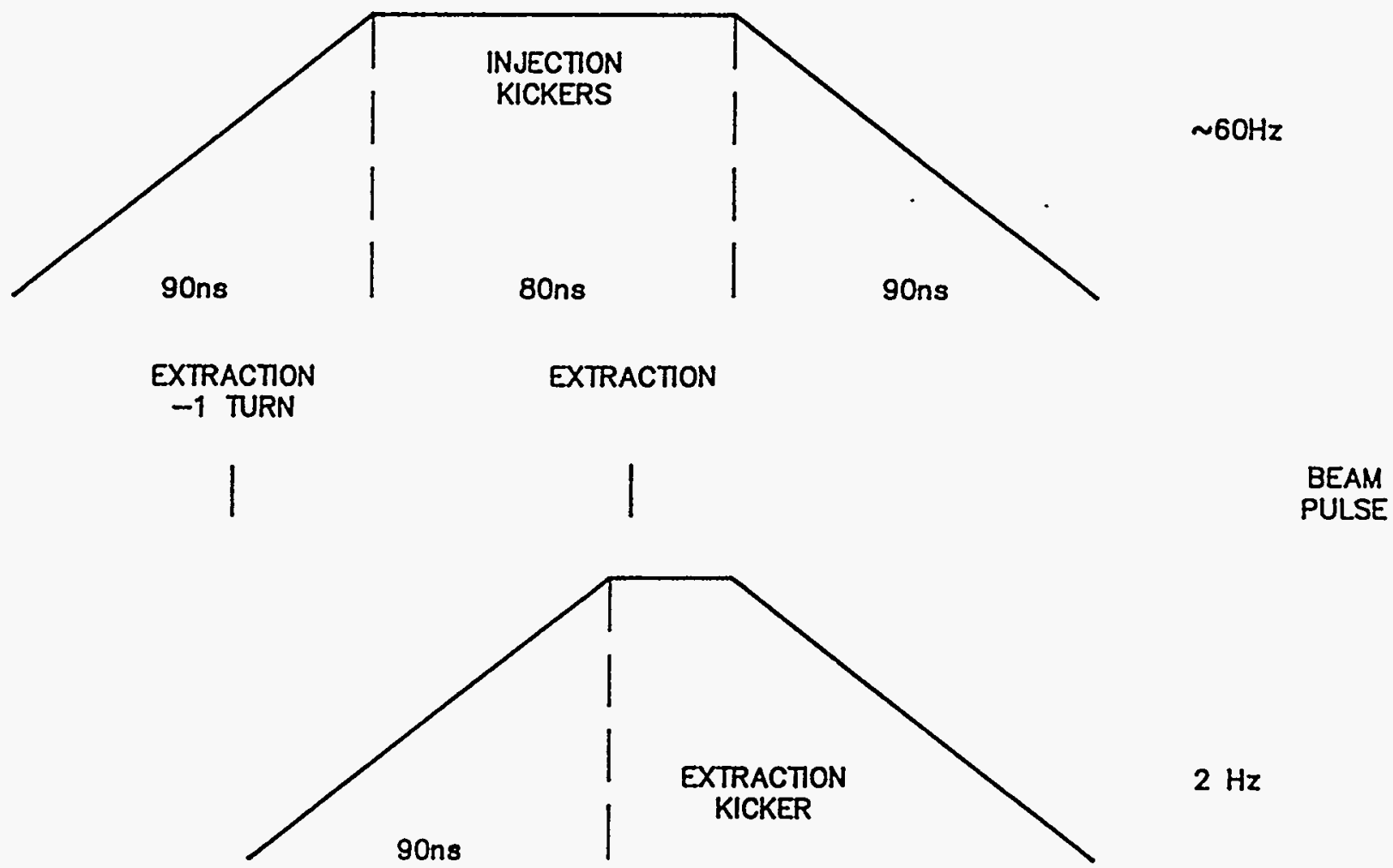

Fig. 8. Time variation of the injection and extraction kicker fields and injected and coasting beam pulses. One injection kicker and the extraction kicker are used together to extract the beam. 


\section{BRRATA}

\section{A Positron Accunulator: Bing for APS}

Page 2, IIne $7-352.96-\mathrm{MHz}$

Page 3, line 3

$$
J_{x}=1 \cdot \frac{1}{2 \pi} \int_{\operatorname{mag}} \frac{D(s)}{\rho^{2}} \cdot(1-2 n) d s
$$

Page 3, line 5

$$
n=\frac{-p B^{\prime}(x)}{B_{0}}(f i e l d \text { index })
$$

Page 15: Table III, Main Dipoles (DC)

$$
\text { Aperture vacuum chamber, } 12 \mathrm{~cm} \times 3.6 \mathrm{~cm}
$$

\section{DISCLAIMER}

This report was prepared as an account of work sponsored by an agency of the United States Government. Neither the United States Government nor any agency thereof, nor any of their employees, makes any warranty, express or implied, or assumes any legal liability or responsibility for the accuracy, completeness, or usefulness of any information, apparatus, product, or process disclosed, or represents that its use would not infringe privately owned rights. Reference herein to any specific commercial product, process, or service by trade name, trademark, manufacturer, or otherwise does not necessarily constitute or imply its endorsement, recommendation, or favoring by the United States Government or any agency thereof. The views and opinions of authors expressed herein do not necessarily state or reflect those of the United States Government or any agency thereof. 